\title{
El patrimonio de la
}

\section{humanidad en Andalucía}

\author{
Jorge Benavides Solís \\ ICOMOS España
}

La Convención para la Protección del Patrimonio Cultural y Natural aprobada por la Conferencia General de la UNESCO hace veinticinco años (1972), tiene por objeto la salvaguardia de los bienes que, ubicados en todos los continentes y de todas las épocas (Cuevas de Altamira, Estatua de la Libertad, Brasilia), por su valor extraordinario y su carácter excepcional constituyen un patrimonio de toda la humanidad. En las "Orientations davant guider la mise en oeuvre de la Convention du patrimonie mondial" traducidas por De Prada Bengoa en el Boletín n ${ }^{\circ} 17$ del Instituto del Patrimonio Histórico Andaluz, se encuentran tipificados los posibles bienes de dicho inventario: Monumentos, Conjuntos (Ciudades muertas y ciudades históricas), Sitios y dentro de estos, los Paisajes Culturales (concebidos, evolutivos, asociativos).

Las primeras dos ciudades: Quito (Ecuador) y Cracovia (Polonia) fueron inscritas por la UNESCO en el Registro del Patrimonio de la Humanidad en 1979. Como la adhesión de España a dicha Convención recién se produjo en 1982, las ciudades españolas se comenzaron a inscribir a partir de 1985: "Centro Histórico de Córdoba, Ciudad vieja de Segovia y su acueducto, Ciudad vieja de Santiago de Compostela, Ciudad vieja de Ávila con sus iglesias extramuros, Ciudad histórica de Toledo, Ciudad vieja de Cáceres, Ciudad vieja de Salamanca", Como se aprecia y desde hace poco tiempo sólo una es andaluza pues, su anterior inscripción comprendía únicamente la Mezquita. Granada no consta como ciudad sino como conjunto: Alhambra, Generalife y el Albaicín. De forma similar Sevilla: Catedral, Alcázar y Archivo de Indias.

En 1989 el Comité del Patrimonio Mundial constituido por representantes de Brasil, Bulgaria, Canadá, Colombia, Estados Unidos, Francia, Grecia, India, Indonesia, Italia, Méjico, Omán, Pakistán, Perú, Siria, Tanzania, Senegal, Tailandia y Túnez, denegó la inscripción de Úbeda y Baeza. En 1992 el grupo parlamentario del Partido Popular, presentó una proposición no de Ley de "Apoyo a la petición de la Diputación Provincial de Jaén para que Úbeda y Baeza sean declaradas Patrimonio de la Humanidad" y hasta la fecha, no se ha logrado el objetivo deseado; sin embargo se han inscrito otros bienes. Los últimos, en 1996: la Loja de la Seda de Valencia y la Villa Histórica fortificada de Cuenca con lo cual suman un total de veintitres distribuidos así: Andalucía 4; Aragón I; Asturias I; Canarias I; Cantabria I; Castilla y León 4; Castilla la Mancha 2; Cataluña 4 (de Gaudí 3); Extremadura 3; Galicia I; Madrid I; Valencia I; y varios I (el Camino de Santiago) (I).

Si bien, la tramitación al respecto le corresponde al Ministerio de Cultura, desde 1985, la responsabilidad cultural por obvias razones, le corresponde a la Dirección General de Bienes Culturales de la Consejería de Cultura cuya estrategia para incorporar todos los más auténticos y representativos testimonios del antiguo, variado y singular proceso cultural de Andalucía no debería postergarse por más tiempo.

Ya en 1993 en un artículo publicado en El País, tuve oportunidad de advertir que a raíz de la dura experiencia de la guerra de Yugoslavia, la UNESCO se había visto obligada a reflexionar en términos prácticos sobre la inscripción de los bienes culturales en el Patrimonio de la Humanidad: "La incorporación formal no basta (Las Convenciones Internacionales de La Haya en caso de conflictos armados y de Protección del Patrimonio Mundial resultaron insuficientes para impedir los bombardeos de Split y Dubrovnik y luego para afrontar su restauración). A veces incluso puede resultar contraproducente. Hacen falta medios y recursos para la protección y éstos, a más de limitados no son interminables. Italia, por sus particulares características, ya en 1992 puso en evidencia que era indispensable poner un tope, un número clausus al inventario. Por su parte, los países que todavía no se habían adherido a la Convención expresaron su inconformidad. Canadá propuso que se determinase un plazo para la adhesión de los países a la Convención y otro para solicitar la incorporación de todos los bienes (culturales y naturales) que ellos creyeren conveniente". No se ha llegado a adoptar una postura definitiva; sin embargo, por recomendación, actualmente los países signatarios están elaborando una "Lista tentativa o indicativa" con todos los bienes que durante un plazo máximo de entre quince y veinte años serán susceptibles de ser presentados para su inscripción en el Patrimonio Mundial. Se trataría pues, de una lista "cerrada" de candidaturas mas no de futuras inscripciones obligatorias. Italia, Francia y otros países europeos, desde 1992 están confeccionando listas 
constituidas por más de trescientos bienes. Por su parte, el Ministerio de Cultura de España, hasta fines del año pasado (1996) disponía de una lista de noventa bienes para todo el territorio nacional entre los cuales se han incluido a seis de carácter cultural y a cuatro de carácter natural en Andalucía. Pocos, si se toma en cuenta la extensión del territorio, su variado paisaje, su amplia diversidad cultural y su indudable protagonismo histórico en el extraordinario período del Al Andalus y luego durante su relación con América (Cataluña que posee una superficie tres veces menor a la de Andalucía ha conseguido incorporar ocho bienes en la Lista del Ministerio). Insisto una vez más: ¡cómo no va a ser un Paisaje Cultural de valor Universal "El Rocío" y la Semana Santa de Sevilla!. Y dentro de esta tipología, ¿por qué no las rutas Andaluci? Acaso, como hecho histórico/cultural de convivencia de judíos, musulmanes y cristianos no es excepcional y único?. Y ipor qué no la ruta de los "Pueblos blancos" y otros monumentos, conjuntos, sitios y paisajes culturales/ naturales?

La relación entre superficie o población con el número de bienes culturales con valor suficiente para ser reconocidos como patrimonio de la humanidad tiene mucha relatividad, es cierto, pero si se amplía a nivel continental, adquiere una expresividad digna de ser tomada en cuenta. Europa tiene más bienes inscritos que Asia y África juntas. El hecho se explica con facilidad. Solamente los países firmantes de la Convención del Patrimonio de la Humanidad tienen la posibilidad de solicitar la inscripción de sus bienes más representativos. Todos los países europeos lo han hecho, no así aquellos de otras partes del mundo. Si permaneciera en ciento cuarenta el número total de países, la Organización de Naciones Unidas para la Ciencia, la Educación y la Cultura (UNESCO) se vería obligada a precisar el alcance del Inventario del Patrimonio de la Humanidad. Sería de algunos países pero no de la Humanidad. Y como es lógico, la aspiración máxima es conformar un inventario completo conformado por las obras del más alto significado a través de las cuales, en realidad, sea posible hacer un recorrido completo, no de la aventura del hombre propenso a ubicarse en países para escribir sus reducidas historias nacionales, o a destacar su identidad cultural, en todos los casos excluyente $o$, a resaltar sus diferencias, ya sean sociales, de color, religiosas o de costumbres, de difícil aceptación sino, la aventura del ser humano único y planetario con una sola historia y a la vez con todas sus identidades y todas sus diferencias. Un patrimonio que, entonces sí como factor de consenso, sea integrador y a la vez haga propicia la paz. Por ello el auténtico Patrimonio de la Humanidad debería conformarse tomando en cuenta aquellos bienes que hipotéticamente estuvieran ubicados incluso en países no adheridos a la Convención de 1972 siempre y cuando sean un testimonio indispensable del genio creador del ser humano desde sus orígenes hasta el momento actual.

Suponer, por ejemplo, la omisión de los yacimientos africanos que marcan el origen del hombre sería inaceptable, como lo habría sido la omisión del Archipié- lago de las Galápagos (Ecuador) el primer bien natural inscrito en 1979 en donde Darwin encontró la justificación de su teoría de la evolución de las especies. Sería un error así mismo postergar indefinidamente la inscripción de bienes del siglo XX. Hasta el momento solamente se han reconocido dos: Brasilia y el Campo de Concentración de Auschwitz.

La Convención de la que se derivó el inventario del Patrimonio de la Humanidad, surgió a raíz de la construcción de la presa de Asuán construida en los años sesenta. La comunidad internacional se conmovió y tomó conciencia, quizá con intensidad, por primera vez del peligro de pérdidas irreparables, es decir, tuvo un fin inmediato: la protección. Sin embargo, después de una experiencia de veinticinco años aquel propósito se ha ido matizando con otros aspectos de suma importancia ante los cuales el ICOMOS, como asesor inmediato de la UNESCO, no ha querido mantenerse indiferente. La reflexión sobre esos matices, a manera de preguntas, la trasladó a sendos Seminarios de Expertos reunidos en Helsinki ( 1995) y en México (1996): "¿cómo evitar el eurocentrismo y conseguir una equilibrada representatividad geográfica? ¿Cómo pueden ser respetadas las recomendaciones del "estudio estratégico global?; ¿qué debería ser incluido en la definición del Patrimonio del siglo XX?; ¿cuál debe ser el objetivo de este reconocimiento?". El estudio global estratégico, en la acepción francesa, trata de definir las "Provincias culturales" con el fin de que, también la representación cultural sea equilibrada.

Las conclusiones de dichos Seminarios, dentro de su generalidad característica, tienen un componente pragmático que obvia las posibles discusiones o divergencias, por ejemplo con respecto a los criterios para determinar aquellas "provincias culturales". En general, en las recomendaciones internacionales queda en pie todo aquello que en francés y en inglés a nivel conceptual resulta cómodo comprender y aceptar aunque en español no lo sea. Por ejemplo, "World Heritage, literalmente traducido sería patrimonio mundial. En castellano es preferible decir, Patrimonio de la Humanidad. El primero tiene una connotación geográfica indudable, en español en cambio hace referencia al hombre por lo cual su relación con el Patrimonio Cultural aparece más lógica e inmediata. Esta matización adquiere muchísima importancia en el momento de valorar un bien como representante de una región geográfica del mundo o de la evolución de la Historia de la Humanidad, es decir, de todos los hombres, de todos los países, se ubiquen en cualquier sitio o hayan transitado por cualquier región. De ahí que la "región cultural" no tenga por qué coincidir con aquella geográfica." (I)

¿Cómo determinar "la provincia geográfica" a la que pertenecería Andalucía? Si tomamos como preponderante la referencia geográfica, podría identificarse como perteneciente a la región cultural europea pero quizá más obvia sería su pertenencia a la región cultural mediterránea. Si tomamos en cuenta los siete siglos de presencia musulmana, valorados en un gran número de bienes inscritos en el Patrimonio de la Humanidad,
I. Jorge Benavides Solís en: "Seminario sobre la Conservación del Patrimonio del Siglo XX". ICOMOS/U.A. Metropolitana. México 1996:50


no se podría negar su cercanía, aunque no su pertenencia plena a la región cultural del norte de África, geográficamente, como la judía, también mediterránea. Tomando en cuenta la religión, la pertenencia al tronco común judeo/cristiano/musulmán ratificaría el anterior parentesco. Pero si, como dijo María Zambrano, la patria es el idioma, Andalucía pertenecería a una región cultural que compromete a más de trecientos cincuenta millones de habitantes de cuatro continentes: Europa, África, América y Asia. La experiencia histórico-cultural de Andalucía, va más allá de cualquier división pragmática posible y en consecuencia su situación es privilegiada. Por eso, en ninguna otra parte del mundo, en este momento podría confluir tanta diversidad con absoluta comodidad: todos los países americanos, por razones obvias, los de Europa, los del norte de África, los Sefarditas, los guineanos y filipinos. Patria cuyo perfil omite a los santos y a los héroes (no los tiene), ha mantenido en permanente vigencia el paganismo tolerante como expresión de agradable convivencia con la naturaleza gracias a lo cual todos los pueblos que han llegado a su seno, se han integrado plenamente.

Andalucía pues, sin lugar a duda, es uno de los imprescindibles escenarios en donde han acaecido algunos de los hechos más significativos en la historia del ser humano y a la vez se ha mantenido como opción convergente de tolerancia, convivencia y paz. Estas fueron las razones que motivaron al Secretario General de la UNESCO su simpatía por el proyecto presentado en conjunto con la E.T.S.A de Sevilla para crear un CENTRO INTERREGIONAL DE INFORMACIÓN Y APOYO TÉCNICO AL PATRIMONIO CULTURAL DE LA HUMANIDAD DE IBEROAMÉRICA Y EL MEDITERRÁNEO. Iniciativa que, en la era de la informática, todavía está esperando un respaldo más amplio y práctico.

Hacer todo lo posible para que logre conformarse y protegerse un auténtico inventario del Patrimonio de la Humanidad supone un compromiso para dar cumplimiento con los objetivos de la Convención de 1972 pero también una agradable responsabilidad de contribuir para que se perfilen las referencias materiales imprescindibles de la memoria universal que omite fronteras. Una especie de mapa genético de la experiencia del ser humano que en el futuro debería convertirse en una referencia en la cual podrían fundamentarse tipos de iniciativas provenientes del ámbito público y privado, no gubernamental, académico, etc. para el conocimiento, la protección, la difusión, la consulta, la gestión, la cooperación internacional, el intercambio.

\section{PATRIMONIO DE LA HUMANIDAD EN ESPAÑA}

\begin{tabular}{|c|c|c|}
\hline CC. AA. & NOMBRE & AÑO DE INSCR. \\
\hline Andalucía & $\begin{array}{l}\text { Mezquita de Córdoba/extensión como Ctro. Hist. } \\
\text { Alhambra, Generali/ext. incluye Albaicín. Granada } \\
\text { Parque Nacional Doñana } \\
\text { Catedral, Alcázar y Archivo de Indias. Sevilla }\end{array}$ & $\begin{array}{r}1984 / 1994 \\
1984 / 1994 \\
1994 \\
1987\end{array}$ \\
\hline Aragón & Arquitectura mudéjar de Teruel & 1986 \\
\hline Asturias & Conjunto prerrománico asturiano & 1985 \\
\hline Canarias & Parque nacional de Garajonay. Gomera & 1986 \\
\hline Cantabria & Cueva de Altamira en Santillana del Mar & 1985 \\
\hline Castilla Ln. & $\begin{array}{l}\text { Cdad. antigua e iglesias extramuros de Avila } \\
\text { Catedral de Burgos } \\
\text { Cdad. antigua de Salamanca } \\
\text { Cdad. antigua y acueducto de Segovia }\end{array}$ & $\begin{array}{l}1985 \\
1984 \\
1986 \\
1985\end{array}$ \\
\hline Castilla M. & $\begin{array}{l}\text { Recinto histórico de la ciudad de Cuenca } \\
\text { Cdad. histórica de Toledo }\end{array}$ & $\begin{array}{l}1996 \\
1986\end{array}$ \\
\hline Cataluña & $\begin{array}{l}\text { Parque y palacio Güel, casa Mila de Barcelona } \\
\text { Monasterio de Poblet en Vimbodí }\end{array}$ & $\begin{array}{l}1984 \\
1991\end{array}$ \\
\hline Extremadura & $\begin{array}{l}\text { Conj. arqueológico de Mérida } \\
\text { Cdad. antigua de Cáceres } \\
\text { Monasterio de Guadalupe }\end{array}$ & $\begin{array}{l}1993 \\
1986 \\
1993\end{array}$ \\
\hline Galicia & Cdad. antigua de Santiago de Compostela & 1985 \\
\hline Madrid & Monasterio y sitio de El Escorial & 1984 \\
\hline Valencia & Lonja de la Seda & 1996 \\
\hline Varios & Camino de Santiago & 1993 \\
\hline
\end{tabular}

